\title{
Rare coexistence: type A aortic interruption and left ventricular non-compaction
}

\author{
Yahya Kemal içen ${ }^{1}$, Ayşe Selcan Koç² \\ ${ }^{1}$ Cardiology Department, Adana City Hospital, Health Science University, Adana, Turkey \\ ${ }^{2}$ Radiology Department, Adana City Hospital, Health Science University, Adana, Turkey
}

Adv Interv Cardiol 2018; 14, 2 (52): 212-213

DOI: https://doi.org/10.5114/aic.2018.76420

Left ventricular non-compaction (LVNC) is an anomaly characterized by deep trabeculations within the left ventricular cavity. This anomaly, described by Chin et al. [1]. in 1990, was added to the cardiomyopathy classification in 2006. Aortic interruption (Al), first described by Steidele in 1778, occurs in one in three million births [2]. The coexistence of these two rare anomalies is much less common.

A 48-year-old male patient was admitted to the cardiology polyclinic with a feeling of pressure in the chest area. There was no disease in his background. On physical examination, the patient's blood pressure measured $145 / 90 \mathrm{~mm} \mathrm{Hg}$ and there was a systolic murmur with no spread of 1-2/6 on the aortic focus. Electrocardiography (ECG) was normal. An exercise ECG test was requested and interpreted as positive. Evaluation of the echocardiography revealed that the ejection fraction was $55 \%$, and hypertrabeculation was observed in the left ventricle. The non-compacted layer was $2.2 \mathrm{~cm}$ and the compacted layer was $0.8 \mathrm{~cm}$ (Figure $1 \mathrm{~A}$ ). A stable angina diagnosis was considered and the patient was transferred to the coronary angiography (CAG) laboratory. The right femoral region was punctured, and the guide wire could not pass into the distal section of the descending aorta. A simultaneous right radial approach was performed. In angiography, non-critical lesions were observed in the coronary arteries. Hypertrabeculation was observed in the left ventriculography (Figure $1 \mathrm{~B}$ ). A pigtail catheter was placed in the aorta from the radial route and descending from the femoral route. Simultaneous aortography was performed where the descending aorta discontinued before the exit of the subclavian artery, accompanied by a giant collateral vessel (Figure $1 \mathrm{C}$ ). The discontinuity at the descending aorta and giant collateral artery was confirmed with three dimensional computed tomography angiography (Figure $1 \mathrm{D})$. Type A Al and LVNC were diagnosed and the patient was discharged with suggestions of medical treatment.

Left ventricular non-compaction and $\mathrm{Al}$ are very rare anomalies individually. Left ventricular non-compaction is a known reason for cardiomyopathy. If not diagnosed at an early stage, the patient could present with cardiac insufficiency symptoms and the patient could be lost at an early stage. Some morphological diagnostic criteria have been accepted for LVNC with echocardiography. Compacted epicardial bands and thicker non-compacted endocardial layers have been observed in echocardiography. A maximum end systolic ratio of non-compacted to compacted layers greater than 2 was accepted as the diagnosis for LVNC. In our patient, the ratio of non-compacted to compacted layers was greater than 2. Because the patient had claustrophobia, the diagnosis of LVNC could not be confirmed with magnetic resonance imaging (MRI). Al is a congenital anomaly. In patients with good collateral circulation, the diagnosis is made at an older age. The classification, made by Celoria et al. [3], lists three types: type A, B, C. If the aorta is interrupted at the distal part of the left subclavian artery it is called type $A$; if the aorta is interrupted between the left subclavian and left common carotid artery, it is called type B; if the aorta is interrupted after the common carotid artery, it is called type C. In our case, the descending aorta did not continue before arriving at the left subclavian artery, so it is defined as type A. The coexistence of Al and LVNC is very rare, and we found only one case which was published in 2015 in the literature review [4].

Even if LVNC and Al coexistence is very rare, it has to be kept in mind. Suspected patients may require further investigation, such as computed tomography angiography or magnetic resonance angiography.

\section{Corresponding author:}

Yahya Kemal İçen MD, Cardiology Department, Adana City Hospital, Health Science University, 01000 Adana, Turkey, phone: +90 5437720025, e-mail: dryahyakemalicen@gmail.com

Received: 25.12.2017, accepted: 19.02.2018. 

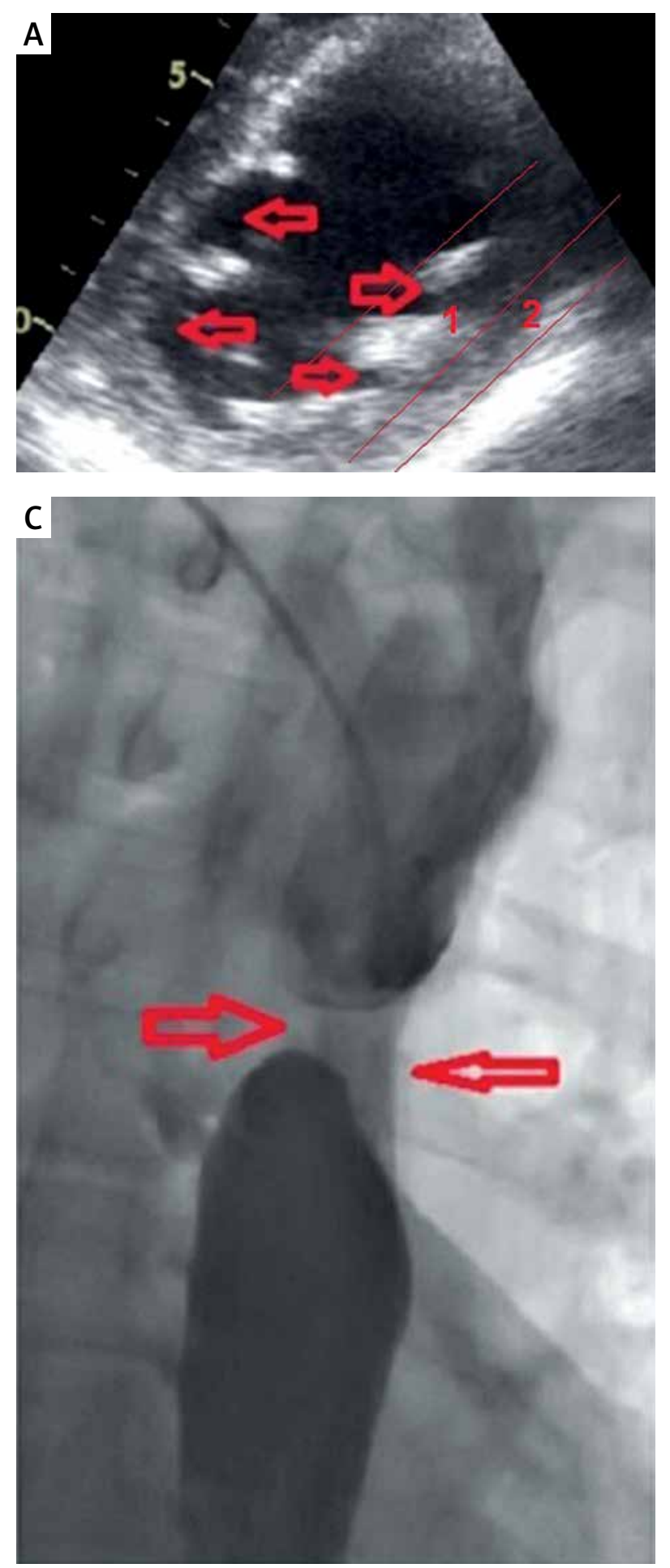

\section{Conflict of interest}

The authors declare no conflict of interest.

\section{References}

1. Chin TK, Perloff JK, Williams RG, et al. Isolated noncompaction of left ventricular myocardium. A study of eight cases. Circulation 1990; 82: 507-13.

2. Steidele RJ. Samml Chir u Med Beob (Vienna) 1778; 2: 114.
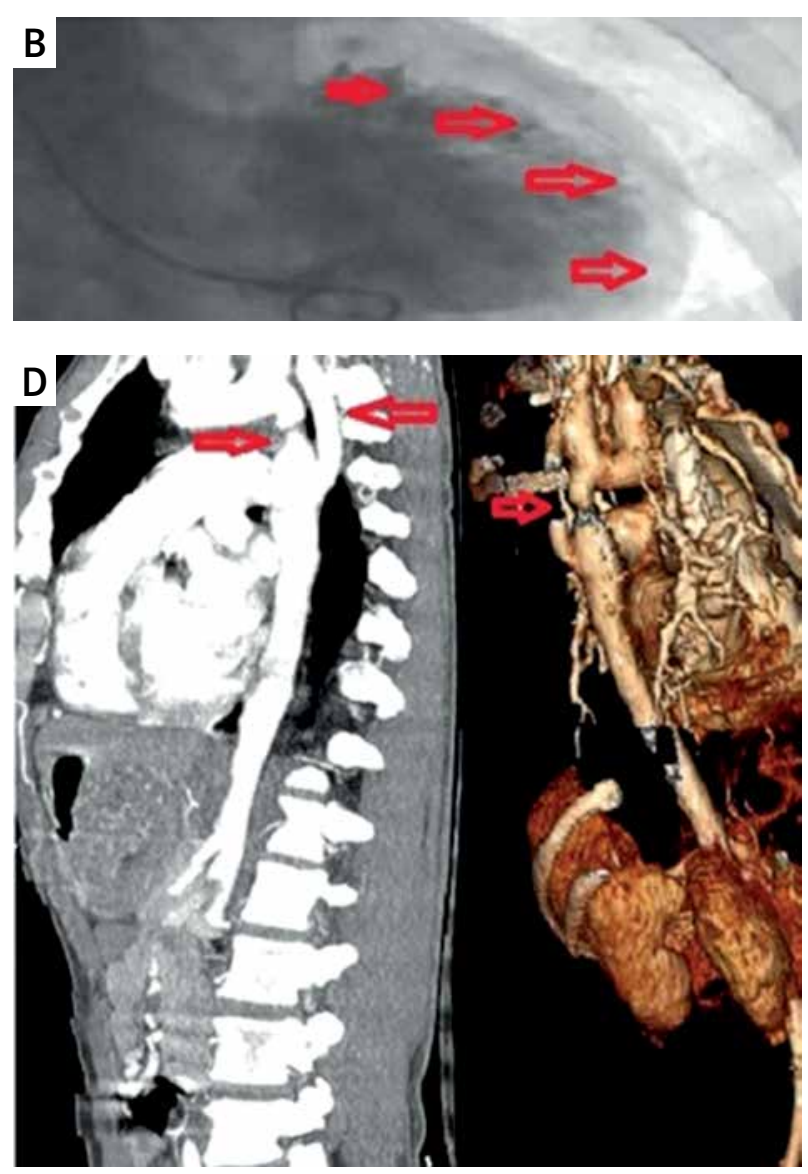

Figure 1. A - Showing deep trabeculations (red arrows) and non-compacted layer (1) and compacted layer (2) with transthoracic echocardiography in parasternal short axis projection. B - Showing deep trabeculations (red arrows) with ventriculography. $\mathbf{C}$ - Showing interrupted segment and giant collateral in aorta (red arrows) with aortography. D - Showing interrupted segment and giant collateral in aorta (red arrows) with 3D computerized tomography

3. Celoria GC, Patton RB. Congenital absence of the aortic arch. Am Heart J 1959; 58: 407-13.

4. Isilak Z, Incedayi M, Aribal S, et al. Coexistence of left ventricular noncompaction and aortic interruption. Echocardiography 2013; 30: E220-1. 